\title{
Sosialisasi peranan sertifikat halal bagi masyarakat Kelurahan Kampung Baru, Kecamatan Senapelan, Kota Pekanbaru
}

\author{
Irdha Mirdhayati*1, Wieda Nurwidada H. Zain ${ }^{1}$, Eko Prianto $\unrhd^{2}$, Muhammad Fauzi $\oplus^{2}$ \\ ${ }^{1}$ Fakultas Pertanian dan Peternakan, UIN Sultan Syarif Kasim Riau \\ ${ }^{2}$ Fakultas Perikanan dan Kelautan, Universitas Riau \\ * mirdhayati@gmail.com
}

\begin{abstract}
Abstrak. Tujuan pengabdian masyarakat ini adalah untuk memberikan pengetahuan dan pemahaman tentang sertifikat halal kepada masyarakat, meningkatkan kesadaran masyarakat tentang arti penting sertifikat halal dan memotivasi masyarakat agar memiliki sertifikat halal bagi yang memiliki usaha yang termasuk dalam lingkup produk halal. Metode pengabdian dilakukan dengan cara sosialisasi peranan sertifikat halal, pemberian kuisioner kepada peserta dan evaluasi kuisioner. Parameter kesadaran halal masyarakat ditinjau dari pengetahuan umum tentang hukum halal, kesadaran masyarakat tentang implementasi produk halal dan pengetahuan umum tentang peranan sertifikat halal. Hasil evaluasi sosialisasi menunjukkan bahwa semua peserta memiliki pengetahuan umum tentang hukum halal secara baik, semua peserta memiliki tingkat kesadaran implementasi penggunaan produk halal yang tinggi dan semua peserta memiliki pengetahuan yang baik mengenai peranan dan pengurusan sertifikat halal. Hasil diskusi langsung dengan peserta menjelaskan bahwa pelaku usaha mikro belum memiliki sertifikat halal dikarenakan sosialisasi tentang pengurusan sertifikat halal yang sangat kurang dilakukan oleh Pemerintah dan sebagian masyarakat masih belum mengetahui tentang adanya UU Jaminan Produk Halal yang mewajibkan bahwa semua produk yang beredar dan diproduksi di Indonesia wajib memiliki sertifikat halal. Dapat disimpulkan bahwa pengetahuan dasar hukum halal dan kesadaran halal yang tinggi saja belum cukup untuk menjamin tingginya keinginan pelaku usaha mikro untuk mengurus sertifikat halal.
\end{abstract}

Kata kunci: sosialisasi, sertifikat halal, kesadaran masyarakat, usaha mikro

\begin{abstract}
The purpose of this community service was to provide knowledge and understanding of halal certificates to the public, increase public awareness of the importance of halal certificates and motivate the community to have halal certificates for those who have businesses in the scope of halal products. The service method was carried out by socializing the role of the halal certificate, giving questionnaires to participants and evaluating the questionnaire. The parameters of public halal awareness are reviewed from general knowledge about halal law, public awareness about the implementation of halal products and knowledge about the role of halal certificates. The results showed that all participants had good general knowledge of halal law, had high level of awareness of the implementation of the use of halal products and all participants have good knowledge about the role and management of halal certificates. The results of direct discussions with participants explained that micro business actors do not have a halal certificate due to the lack of socialization regarding halal certificate management by the Government. It can be concluded that basic knowledge of halal law and high awareness of halal are not sufficient to guarantee the high desire of micro-entrepreneurs to apply for halal certificates.
\end{abstract}

Keywords: socialization, halal certificate, public awareness, micro-enterpreneurs

To cite this article: Mirdhayati, I., W. N. H. Zain., E. Prianto., M. Fauzi. 2020. Sosialisasi peranan sertifikat halal bagi masyarakat Kelurahan Kampung Baru, Kecamatan Senapelan, Kota Pekanbaru. Unri Conference Series: Community Engagement 2: 117-122. https://doi.org/10.31258/unricsce.2.117-122

(C) 2020 Authors

Peer-review under responsibility of the organizing committee of Seminar Nasional Pemberdayaan Masyarakat 2020 


\section{PENDAHULUAN}

Halal merupakan syarat utama bagi konsumen muslim dalam mengkonsumsi produk pangan. Kehalalan produk pangan ditentukan dari kesesuaian proses, bahan baku hingga transportasi dari tahap hulu ke hilir produk sampai ke tangan konsumen. Produk halal saat ini memiliki pangsa pasar yang besar dan terus berkembang. Hal itu disebabkan karena pertumbuhan populasi muslim sebanyak 1,8 miliar pada tahun 2015 dan Asia Pasifik mendominasi pasar dengan menyumbang USD 594 miliar pada tahun 2016, dengan basis konsumen yang besar di banyak negara seperti Pakistan, Indonesia, Bangladesh dan India dengan populasi Muslim yang tertinggi (Cooper, 2017 dalam Ma'rifat, 2017).

Melihat potensi pasar yang sangat besar dan Indonesia sebagai negara muslim terbesar di dunia saat ini maka pemerintah berusaha untuk mensyaratkan sertifikasi halal bagi setiap pelaku usaha. Karena Indonesia juga menjadi pasar besar produk impor baik pangan, obat, kosmetik dan barang gunaan lainnya (Farhan, 2018). Namun saat ini banyak masyarakat yang belum memahami dengan baik sertifikasi halal tersebut sehingga sebagian besar pelaku usaha dan masyarakat belum memilikinya. Agustina et al. (2019) menyatakan bahwa sertifikasi halal adalah suatu proses untuk memperoleh sertifikat halal melalui beberapa tahap pemeriksaan untuk membuktikan bahwa bahan, proses produksi, dan sistem jaminan halal memenuhi standar Lembaga Pengkajian Pangan Obat-obatan dan Kosmetika Majelis Ulama Indonesia (LPPOM MUI). Adapun tujuan sertifikasi halal yaitu untuk memberikan kepastian status kehalalan suatu produk sebagai bentuk pemenuhan hak konsumen. Keyakinan konsumen terhadap kehalalan suatu produk akan mempengaruhi jumlah pembelian konsumen terhadap produk tersebut.

Isu sertifikat halal merupakan polemik yang sedang beredar di masyarakat sejak mulai diberlakukannya implementasi UU Jaminan Produk Halal nomor 33 Tahun 2014 pada tanggal 17 Oktober 2019 lalu. Pengurusan sertfikat halal sering dianggap mempersulit masyarakat dalam menjalankan usahanya. Oleh sebab itu perlu dilakukan kegiatan edukasi dan sosialisasi kepada masyarakat untuk menanamkan kesadaran penerapan halal yang tinggi dan memiliki pengetahuan serta pemahaman yang benar tentang penerapan sertifikasi halal menurut undang-undang yang telah ditetapkan.

Kelurahan Kampung Baru Kecamatan Senapelan merupakan salah satu destinasi wisata bagi masyarakat Kota Pekanbaru. Kelurahan Kampung Baru terletak di pesisir Sungai Siak yang merupakan salah satu objek wisata yang ramai dikunjungi masyarakat. Setiap harinya masyarakat Kampung Baru banyak yang berjualan makanan disekitar lokasi wisata terutama pada sore hingga malam hari. Selain dari wisata sungai, Kampung Baru juga memiliki "Rumah Batin" merupakan cagar budaya berisikan informasi asal usul lahirnya Kota Pekanbaru. Adanya objek wisata dan cagar budaya inilah menjadikan Kampung Baru sebagai destinasi masyarakat Kota Pekanbaru. Hingga saat ini para pedagang di Kampung Baru belum memiliki sertifikasi halal dan sebagian besar masyarakat juga belum memahami terkait dengan sertifikasi halal tersebut. Mengingat sertifikasi ini sangat penting bagi masyarakat Kampung Baru, maka perlu dilakukan sosialisasi sertifikasi halal ini.

Tujuan Pengabdian ini adalah untuk memberikan pengetahuan dan pemahaman tentang sertifikat halal kepada masyarakat, meningkatkan kesadaran masyarakat tentang arti penting sertifikat halal dan memotivasi masyarakat agar memiliki sertifikat halal bagi yang memiliki usaha yang termasuk dalam lingkup produk halal. Manfaat yang diharapkan dari pengabdian ini adalah masyarakat memiliki kesadaran halal yang tinggi, memiliki pengetahuan umum tentang produk halal serta memberikan infromasi mengenai kesadaran sertifikasi halal di Kelurahan Kampung Baru.

\section{METODE PENERAPAN}

Kegiatan Pengabdian ini dilakukan pada tanggal 23 Juli 2020 bertempat di Kantor Kelurahan Kampung Baru Kecamatan Senapelan Kota Pekanbaru. Peserta kegiatan adalah adalah masyarakat Keluharam Kampung Baru yang berjumlah lima belas orang yang terdiri dari 5 orang laki-laki dan 10 orang wanita, 2 orang diantaranya adalah pemilik usaha mikro. Metode pengabdian dilakukan dengan cara sosialisasi peranan sertifikat halal, pemberian kuisioner kepada peserta dan evaluasi kuisioner. Parameter ukuran kesadaran halal masyarakat diukur dari pengetahuan umum tentang hukum halal, kesadaran masyarakat tentang implementasi produk halal dan pengetahuan umum tentang peranan sertifikat halal. 


\section{HASIL DAN KETERCAPAIAN SASARAN}

Sosialisasi halal dilakukan di Kantor Lurah Kampung Baru dihadiri oleh pejabat kelurahan, masyarakat dan mahasiswa KKN. Penyampaian materi sosialisasi dilakukan melalui ceramah dan diskusi dengan peserta.

Tabel 1. Jadwal Pelaksanaan dan Materi Kegiatan Pengabdian Masyarakat

\begin{tabular}{cll}
\hline \multicolumn{1}{c}{ Hari/Tanggal } & \multicolumn{1}{c}{ Kegiatan } & \multicolumn{1}{c}{ Pemateri } \\
\hline Kamis/23 Juli 2019 & Sambutan & Lurah Kampung Baru \\
\hline & Ceramah dan diskusi & Dr. Irdha Mirdhayati, M. Si \\
& Materi: Sosialisasi Peranan Sertifikat Halal & Wieda Nurwidada, M. Si \\
& Bagi Masyarakat Kelurahan Kampung Baru & Dr. Muhammad Fauzi, M. Si \\
& Kecamatan Senapelan Kota Pekanbaru & \\
\hline
\end{tabular}

Jumlah peserta sosialisasi sebanyak 15 orang dengan umur bervariasi berkisar 20-60 tahun dengan profesi peserta adalah ibu rumah tangga (IRT) sebanyak 9 orang, pekerja swasta ( 3 orang), wiraswasta ( 2 orang) dan mahasiswa 1 orang. Walaupun peserta yang mengikuti sosialisasi ini belum mewakili profesi sebagian besar masyarakat di Kampung Baru, namun setidaknya kehadiran mereka dapat memberikan gambaran terkait pemahaman masyarakat terhadap sertifikasi halal. Hasil analisis data mengenai pengetahuan umum responden menunjukkan bahwa semua responden sudah pernah mendapat informasi tentang hukum halal dan haram, mengetahui definisi halal, memperhatikan logo halal saat membeli produk, pernah mendengar tentang sertifikasi halal serta sebanyak $66 \%$ mencari informasi tentang prosedur sertifikasi halal. Hasil analisis data mengenai kesadaran halal dan pengetahuan tentang sertifkat halal ditunjukkan pada Gambar 1.
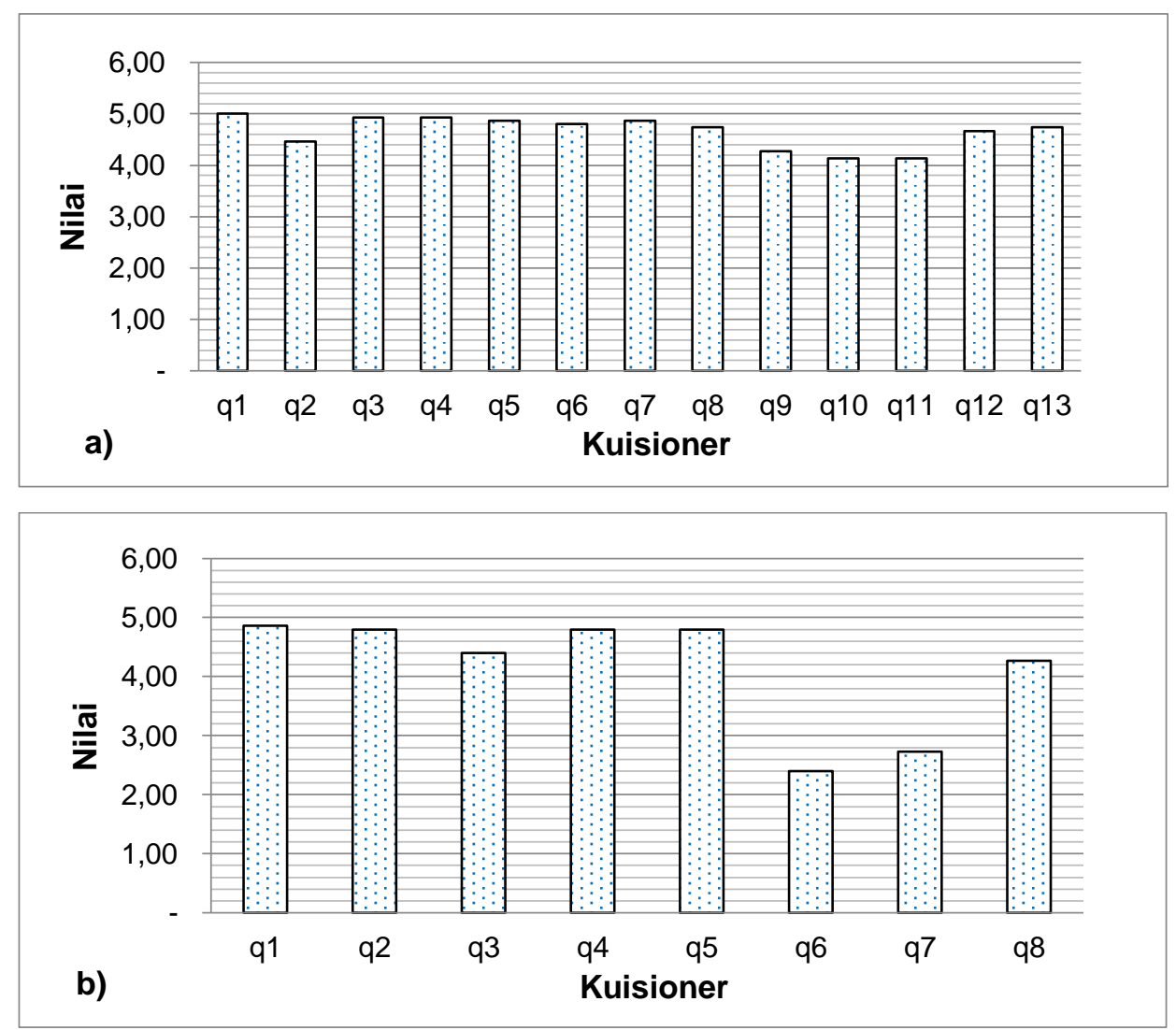

Gambar 1. Nilai rata-rata kesadaran halal masyarakat diukur dari pengetahuan umum tentang hukum halal, a) kesadaran masyarakat tentang implementasi produk halal dan b) pengetahuan umum tentang peranan sertifikat halal 
Pertanyaan yang diberikan untuk mengetahui kesadaran halal responden terdiri atas 13 pertanyaan meliputi pentingnya konsumsi makanan halal, memperhatikan informasi halal produk, komitmen menerapkan, merasa tenang dalam mengonsumsi, menginformasikan produk halal kepada keluarga, merasa kuatir jika produk tidak jelas kehalalannya, beribadah dengan tenang, memperhatikan kehalalan peralatan masak, mengetahui hubungan najis dan hukum halal, jenis jenis najis dan cara menyucikan ruang dan peralatan yang terkena najis, menggunakan kosmetika halal dan berhati-hati dalam memilih obat-obatan dan vaksin. Pada Gambar 1 (a) di atas menunjukkan bahwa semua peserta memiliki tingkat kesadaran implementasi penggunaan produk halal yang tinggi.

Pertanyaan yang diberikan mengenai pengetahuan peranan sertifikat halal terdiri atas delapan (8) pertanyaan yang meliputi : ruang lingkup produk halal, sertifikat halal membantu konsumen muslim, sertifikat halal meningkatkan omset penjualan produsen, sertifikat halal merupakan jaminan kehalalan tertulis dari MUI, sertifikat halal melindungi konsumen muslim, anggapan sertifikat halal memberatkan produsen, sertifikat halal dikeluarkan oleh produsen serta sertifikat halal memudahkan dalam mengekspor produk. Hasil evaluasi menunjukkan bahwa semua peserta memiliki pengetahuan yang baik mengenai peranan sertifikat halal yang ditunjukkan dari Gambar 1 (b). Hampir sebagian besar responden sangat setuju dengan peranan sertifikat halal dalam berusaha dan sebagian besar responden tidak setuju bahwa sertifikat halal memberatkan produsen dan sertifikat halal dapat dikeluarkan oleh produsen.

Hasil diskusi langsung dengan peserta menjelaskan bahwa pelaku usaha mikro belum memiliki sertifikat halal dikarenakan sosialisasi tentang pengurusan sertifikat halal yang sangat kurang dilakukan oleh Pemerintah dan sebagian masyarakat masih belum mengetahui tentang adanya UU Jaminan Produk Halal yang mewajibkan bahwa semua produk yang beredar dan diproduksi di Indonesia wajib memiliki sertifikat halal.

Sosialisasi sertifikasi halal oleh pemerintah saat ini memang belum sepenuhnya merata hingga menjangkau masyarakat bawah sehingga wajar sebagian besar peserta banyak yang belum mengetahui pentingnya sertifikasi ini. Terkait dengan penting produk halal karena mayoritas peserta beragama islam sehingga pemahaman produk halal sudah tertuang dalam ajaran agama islam, sehingga peserta setiap membeli produk selalu memperhatikan label halal. Akim et al. (2018) menyatakan rendahnya pemahaman masyarakat terkait dan belumnya masyarakat memiliki sertifikasi halal disebabkan oleh berbagai alasan, tetapi alasan utama adalah kurangnya pengetahuan, informasi, dan sosialisasi proses sertifikasi halal itu sendiri serta masalahmasalah dalam hal biaya yang harus dikeluarkan untuk melaksanakan sertifikasi halal proses pendaftaran.

Sertifikat halal tidak hanya memberi manfaat perlindungan hukum hak-hak konsumen muslim terhadap produk yang tidak halal, tapi juga meningkatkan nilai jual produk pelaku usaha, karena konsumen tidak akan ragu lagi untuk membeli produk yang diperdagangkan pelaku usaha. Logo sertifikat halal memberikan kepastian hukum kepada konsumen muslim bahwa produk tersebut halal sesuai syariat Islam (Astuti et al, 2020). Selain itu Wa Asrida et al., (2020) menyatakan dengan adanya sertifikasi halal produk sagu tumbu, maka produk yang dihasilkan akan memiliki banyak peluang terutama kepercayaan masyarakat dan pasar sehingga pada akhirnya akan meningkatkan daya saing produk dan omset penjualan.

Pelaksanaan kegiatan ini mendapat respon yang positif bagi peserta karena informasi produk halal merupakan hal yang baru bagi masyarakat. Antusiasme peserta dapat terlihat dari partisipasinya menjawab semua quisioner dan keaktifan mereka dalam melakukan diskusi dan tanya jawab. Untuk meningkatkan kesadaran masyarakat terkait dengan pentingnya produk dan sertifikasi halal perlu dilakukan sosialisasi dan pendampingan yang lebih intensif serta bantuan biaya pengurusan sertifikasi dari pemerintah. Hal ini dilakukan agar sosialisasi halal dapat menjangkau seluruh masyarakat Pekanbaru khususnya di Kelurahan Kampung Baru. Gambar 2. Menunjukkan foto bersama dengan peserta pada saat telah dilaksanakan kegiatan sosialisasi. 


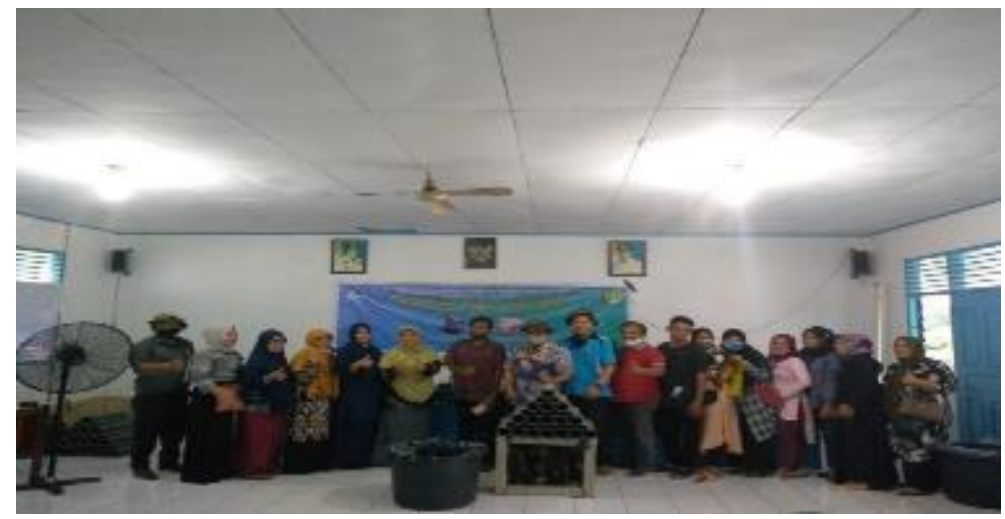

Gambar 2. Sosialisasi sertifikasi halal di Kelurahan Kampung Baru

Adapun hasil positif dari pelaksanaan kegiatan pengabdian ini adalah: pertama) kegiatan pengabdian kepada masyarakat ini dapat menambah pengetahuan dan pemahaman masyarakat Kampung Baru mengenai pentingnya sertifikasi halal, sehingga pelaku usaha dapat mengurus sertifikasi halal pada produk olahannya. kedua) kegiatan pengabdian kepada masyarakat ini mendapatkan respon yang positif dari masyarakat dan aparat pemerintah kelurahan, sehingga mereka berharap kegiatan pelaksanaan perngabdian kepada masyarakat ini dapat dilaksanakan lagi kedepannya.

\section{KESIMPULAN}

Berdasarkan uraian di atas dapat disimpulkan bahwa pengetahuan dasar hukum halal dan kesadaran halal yang tinggi saja belum cukup untuk menjamin tingginya keinginan pelaku usaha mikro untuk mengurus sertifikat halal. Masyarakat selama ini belum mendapat informasi yang mendalam terkait tata cara kepengurusan dan biaya sertifikasi halal ini. Untuk meningkatkan keinginan pelaku usaha untuk mengurus sertifikasi perlu dilakukan pendampingan secara intensif dan bantuan pembiayaan oleh pemerintah.

\section{SARAN}

Sebaiknya kegiatan sosialisasi dan edukasi masyarakat mengenai UU Jaminan Produk Halal dan pentingnya sertifikasil harus dilakukan secara merata dan berkelanjutan oleh Pemerintah baik melalui instansi terkait maupun oleh Perguruan Tinggi sebagai wujud tri dharma perguruan tinggi. Adanya kesadaran masyarakat yang tinggi dan diikuti dengan kemauan melakukan pengurusan sertifkat halal merupakan salah satu bukti bahwa implementasi UU Jaminan Produk Halal sudah dilakukan oleh masyarakat khususnya pelaku usaha mikro dan pelaku usaha kecil.

\section{UCAPAN TERIMA KASIH}

Atas terlaksananya kegiatan ini maka tim pengabdian kepada masyarakat sebagai pelaksana menyampaikan penghargaan dan ucapan terimakasih kepada LPPM Universitas Riau sebagai pihak pemberi dana, Tim KUKERTA Terintegrasi Universitas Riau, Lurah Kampung Baru beserta jajarannya, masyarakat Kelurahan Kampung Baru dan Semua pihak yang telah membantu terlaksananya kegiatan pengabdian ini.

\section{DAFTAR PUSTAKA}

Agustina, Y., H. Pratikto, M. Churiyah, dan B.A. Dharma. 2019. Pentingnya Penyuluhan Sertifikasi Jaminan Produk Halal untuk Usaha Kecil Menengah (UKM). Jurnal Graha Pengabdian, 1(2), 139-150.

Akim, N. Konety, C. Purnama, dan M.H. Adilla. 2018. Pemahaman Usaha Mikro, Kecil dan Menengah (UMKM) di Jatinangor terhadap Kewajiban Sertifikasi Halal pada Produk Makanan. Kumawula, 1(1), 31-49.

Astuti, D., B.S. Bakhri, M. Zulfa, dan S. Wahyuni. 2020. Sosialisasi Standarisasi dan Sertifikasi Produk Halal di Kota Pekanbaru. Berdaya: Jurnal Pendidikan dan Pengabdian Kepada Masyarakat, 2(1), 23-32.

Farhan, A. 2018. Pelaksanaan Sertifikasi Halal LPPOM MUI terhadap Produk Usaha Mikro, Kecil dan Menengah (UMKM) (Studi LPPOM MUI Provinsi Bengkulu). Manhaj: Jurnal Penelitian dan Pengabdian Masyarakat, 3(1), 1-16. 
Ma'rifat, T. N dan M. Sari. 2017. Penerapan Sistem Jaminan Halal pada UKM Bidang Olahan Pangan Hewani. Khadimul Ummah Journal of Social Dedication, 1(1), 39-46.

Wa Asrida, D. Hariyanti, S.A. Musaid dan T.R. Hariyati. 2020. Pelatihan Sertifikasi Halal Produk dan Pengelolaan Keuangan Usaha bagi Kelompok Usaha Sagu Tumbu di Desa Liang Kecamatan Salahutu Kabupaten Maluku Tengah. Jurnal Pengabdian Masyarakat Jamak (Manajemen \& Akuntansi), 3(1), 161-176. 